\section{Thyrotoxic Myopathy}

Brit. med. F., 1966, 1, 90

Chronic thyrotoxic myopathy has been well described before (Hed et al., 1958 ; Gimlette, 1959; Whitfield and Hudson, 1961 ; and others). It is rare, however, for the myopathy to be the main manifestation of thyrotoxicosis. When this does occur, difficulties in diagnosis may arise, as happened in the two cases described below.

\section{CASE 1}

The patient was a woman aged 69 years. In 1960 a diagnosis of cranial arteritis was made, the patient having had a history of angina pectoris, headache, and blurred vision. She had an E.S.R. of $120 \mathrm{~mm}$. in one hour, and a raised $\alpha_{2}$-globulin. A moderate, diffuse enlargement of the thyroid was noted at that time. She responded quite satisfactorily to treatment with prednisolone, which was continued in diminishing doses for three years. In September 1964 she complained of loss of appetite, vague upper abdominal pain, and progressive weakness. Within five weeks she had become so weak that she could not walk. She had lost some weight, but there were no other complaints.

She was a pleasant, co-operative, but anxious-looking patient. Blood-pressure was $170 / 80 \mathrm{~mm}$. Hg. She had auricular fibrillation with a ventricular rate of $100 / \mathrm{min}$. The thyroid gland was moderately enlarged and firm. No bruit could be heard over the gland. She had no exophthalmos, lid lag, or finger tremor. A smooth liver edge was palpable 2 in. $(5.1 \mathrm{~cm}$.) below the costal margin. Muscular weakness was so severe and generalized that she could not turn in bed without help. Comparatively slight muscular atrophy was apparent in the proximal groups of muscles. The cranial nerves were not involved. The reflexes were brisk and equal. There was no sensory loss. She was apyrexial. $\mathrm{Hb}$ was $67 \%$, M.C.H.C. $29 \%$, haematocrit $34 \%$, white cell count $8,000 /$ c.mm., with a normal differential. Reticulocyte count was $4 \%$. E.S.R. was $62 \mathrm{~mm}$. in one hour. Direct Coombs test was negative. No L.E. cells could be found in the peripheral blood. The serum albumin was $2.2 \mathrm{~g} . / 100 \mathrm{ml}$., and the serum globulin $3.2 \mathrm{~g} . / 100 \mathrm{ml}$. Electrophoresis showed raised $\alpha_{2-}$ and $\beta$-globulins. Blood urea and serum electrolytes were normal. The serum bilirubin was $1.2 \mathrm{~g} . / 100 \mathrm{ml}$., and the alkaline phosphatase was 22 KingArmstrong units. The flocculation tests were negative. The level of glutamic oxalacetic transaminase was 100 units. The chest radiographs showed slight cardiac enlargement. A barium-meal examination showed no abnormality in oesophagus, stomach, or duodenum. Microscopical examination of a needle-biopsy specimen of the liver revealed an essentially normal liver architecture with some fatty infiltration and slight increase of dense collagen in the portal tracts.

No definite diagnosis could be made. Polymyalgia rheumatica was considered, but the patient had no pain, and muscular paralysis is not a feature of this disorder. The auricular fibrillation was thought to be due to myocardial ischaemia, of which there was clinical and electrocardiographic evidence. Eventually thyrotoxic myopathy was suspected, and radioactive iodine studies confirmed the diagnosis $(4.4 \%$ of dose excreted in 6-24 hr., thyroid rate factor 0.21 , renal rate factor 0.04 , thyroid/leg ratio at three hours: 225).

On 7 December 1964 she was given a therapeutic dose of radioactive iodine. Improvement in muscle power -was noted by the end of December. When seen in the out-patients department in February 1965 she had recovered completely, and she said that she was able to do all her household duties. She has recently been readmitted with an acute myocardial infarction. The serum bilirubin and alkaline phosphatase levels remain elevated.

\section{CASE 2}

The patient was a man aged 70 years. In 1950 he had a Billroth I gastrectomy for a gastric ulcer. In October 1964 he was admitted to hospital for investigation after complaints of pain in the right leg on walking, weakness in both legs, and loss of weight. On this and on three subsequent admissions no cause could be found to explain the muscle weakness and loss of weight. At one time a post-gastrectomy syndrome was suspected, and proved, when irondeficiency anaemia and steatorrhoea (faecal fats of $9.6 \mathrm{~g}$. in $24 \mathrm{hr}$.) were discovered. Though he improved after a course of oral ampicillin and iron had been given, the muscular weakness remained unchanged. By March 1965 he had such severe generalized muscular weakness that he could not stand without help. There was some muscular atrophy which was apparent in the shoulder-girdle and pelvic-girdle groups of muscles. Tendon reflexes were brisk and equal, and there was no sensory loss. The thyroid gland was not enlarged. He had warm extremities and an anxious, irritable manner, but no other signs of thyrotoxicosis. Thyrotoxic myopathy was confirmed by tracer studies with radioactive iodine $(0.08 \%$ of given dose excreted in $6-24 \mathrm{hr}$., thyroid rate factor 0.32 , renal rate factor 0.03 , thyroid/leg ratio at three hours : 100). A therapeutic dose of radioactive iodine was given on 28 April. By 8 July he had gained $9 \mathrm{lb}$. $(4.1 \mathrm{~kg}$.) in weight and the muscular weakness had completely disappeared.

\section{COMment}

Weakness is a common symptom in thyrotoxicosis, but it is of ten overshadowed by the other symptoms and signs of the disease. It may be the presenting feature and may precede all other signs of thyrotoxicosis, as happened in three of the 20 cases reported by Hed et al. (1958). It is rare, however, for severe myopathy to occur as practically the sole manifestation of thyrotoxicosis. We were unable to find any reference in the literature to cases similar to our own. Nor could we find any reference to the length of the interval in time between the onset of the myopathy and the diagnosis of thyrotoxicosis being made. In our first case it was about 10 weeks and in the second about five months.

In elderly patients complaints of weakness and loss of weight usually raise the suspicion that malignant disease is present. Unlike such patients, sufferers from thyrotoxic myopathy do not look ill and their weakness is both an objective and subjective finding. The clinical picture in our first patient was complicated by her previous history, by the raised erythrocyte sedimentation rate, serum bilirubin and alkaline phosphatase levels, and by the abnormal serum proteins. The cause of these changes still remains obscure, but the return of the muscle power to normal after correction of the thyrotoxicosis puts the diagnosis of thyrotoxic myopathy beyond any doubt. We performed a muscle biopsy before and after treatment. The first specimen showed some atrophy of the muscle fibres, but in neither specimen was there any evidence of myositis or arteritis.

Chronic thyrotoxic myopathy is not as rare as previously thought. We have seen four moderately severe cases in the past two years. We suggest that more cases will be found if the condition is looked for.

I wish to thank Dr. E. V. Cox for permission to publish these cases, and for his patient help and continuous encouragement. I also wish to thank Dr. R. Thompson, who performed the muscle biopsies.

F. Armanious, M.B., B.S., L.M.S.S.A. Medical Registrar, Royal Berkshire Hospital, Reading. Present address: Medical Arts Clinic, Swift Current, Saskatchewan, Canada.

\section{REFERENCES}

Gimlette, T. M. D. (1959). Brit. med. f., 2, 1143.

Hed., R., Kirstein, L., and Lundmark, C. (1958). ₹. Neurol. Neurosurg. Psychiat., 21, 270.

Whitfield, A. G. W., and Hudson, W. A. (1961). Quart. F. Med., 30, 257. 